\title{
DA EXCLUSÃO DO CAMPO À INCLUSÃO NA PRISÃO: A GESTÃo PENAL DA POBREZA AGRÁRIA NO BRASIL
}

\section{FROM THE EXCLUSION OF THE FIELD TO INCLUSION IN PRISON: THE PENAL MANAGEMENT OF AGRARIAN POVERTY IN BRAZIL}

\author{
Bartira Macedo de Miranda* \\ Nayana Guimarães Souza de Oliveira**
}

\begin{abstract}
Resumo: Este artigo apresenta um estudo acerca da gestão penal da pobreza agrária no Brasil, desde a transformação urbana e industrial até a contemporaneidade. Busca-se desvendar os impactos socialmente excludentes e penalmente includentes do rápido processo de urbanização e industrialização ocorridos no Brasil. A hipótese é de que o esvaziamento do campo, pari passu com a expansão das cidades, foi uma das causas do desemprego estrutural e da formação das periferias urbanas, onde está segregada a grande maioria marginalizada da população. Para percorrer este caminho, estuda-se gênese da periferia, construindo uma ponte entre a exclusão do campo e a segregação urbana. Analisa-se como o Estado - no qual se depositam esperanças de realização dos direitos socialmente garantidos - tornou-se cada vez mais um Estado mínimo, com mínimas obrigações. Em sequência, aborda-se o tema da gestão penal da pobreza no Brasil por meio da dilatação da repressão direcionada aos indivíduos pobres, com aumento estratosférico nos gastos públicos direcionados à ampliação de um corpo policialesco. Assim, verifica-se um entrelaçamento entre questão agrária, questão criminal e violência urbana, que perpassa pela transferência da pobreza agrária para as cidades, pela formação das periferias urbanas e pela segregação do pobre neste local, onde ele receberá muito pouco do Estado de Direito e perceberá a presença cotidiana do Estado Penal.
\end{abstract}

Palavras-chave: Direito Agrário; Questão Agrária; Criminologia Crítica; Migrações rural-urbanas; Questão Criminal.

\begin{abstract}
This article presents a study about the criminal management of agrarian poverty in Brazil, from urban and industrial transformation to contemporaneity. It seeks to unravel the socially exclusive and criminally inclusive impacts of the rapid urbanization and industrialization process in Brazil. The hypothesis is that the emptying of the countryside, pari passu with the expansion of cities, was one of the causes of structural unemployment and the formation of urban peripheries, where the marginalized majority of the population is segregated. To follow this path, we study the genesis of the periphery, building a bridge between the exclusion of the countryside and urban segregation. It is analyzed how the State - in which hopes of realizing socially

\footnotetext{
* Bartira Macedo de Miranda é doutora em História da Ciência pela PUC-SP, foi docente do PPGDA entre 2010 e 2016. Atualmente é professora e bolsista produtividade do Programa de Pós-Graduação em Direito e Políticas Públicas, Conselheira Seccional da OAB-GO e diretora da Faculdade de Direito da UFG.

***Nayana Guimarães Souza de Oliveira é mestre em Direito Agrário pela UFG.
} 
guaranteed rights are placed - has become increasingly a minimal State, with minimum obligations. In the sequence, the subject of the criminal management of poverty in Brazil is approached by means of the expansion of the repression directed to the poor individuals, with a stratospheric increase in the public expenses directed to the expansion of a police force. Thus, there is an interweaving between agrarian question, criminal issue and urban violence, which involves the transfer of agrarian poverty to the cities, the formation of urban peripheries and the segregation of the poor in this place, where he will receive very little of the rule of law and will perceive the daily presence of the Criminal State.

Keywords: Agrarian Law; Agrarian Question; Critical Criminology; Rural-urban migration; Criminal Issue.

\section{INTRODUÇÃO}

Na segunda metade do século XX, o Brasil passou por um processo de urbanização e industrialização aceleradas, com a transferência de um grande contingente de pessoas para o ambiente urbano. Neste espaço temporal, as grandes cidades foram alimentadas dia-a-dia por uma massa de gente que deixou as regiões economicamente mais pobres do país para as zonas segregadas do espaço urbano.

A sociedade urbano-industrial no Brasil formou-se entre as décadas de 1930 e 1980, período em que ocorreram diversos movimentos migratórios, tanto do tipo rural-rural, como do tipo rural-urbano. De 1930 a 1950, as migrações destinavam-se ao espaço rural, de modo a atender as demandas de reorganização do setor agroexportador, em especial com fluxos migratórios do Nordeste e norte de Minas Gerais destinados à lavoura cafeeira no interior paulista (SILVA, 2008).

Entre 1940 e 1950, realizaram-se investimentos maciços em infraestrutura e indústria, em virtude do grande afluxo de capital estrangeiro para o país, ocorrendo a formação de um mercado nacional, maior integração do território, expansão do consumo e da urbanização (SANTOS, 1993). O Sudeste, como um todo, passou a receber grandes fluxos migratórios internos, sobretudo vindos do campo, sendo esta migração do tipo rural-urbana, aquela que interessa, neste trabalho, para a percepção das condições estruturais da formação da pobreza urbana.

A década de 1960 é o ponto inicial da trajetória que se procura delinear, pois este foi o momento em que o incremento da população urbana superou o da população rural, ocorrendo um acelerado processo de esvaziamento em massa do campo ${ }^{1}$. É o tempo das migrações do tipo rural-urbana em maior escala e também o início dos grandes problemas causados pela ocupação desenfreada do espaço urbano. 
Da exclusão do campo à inclusão na prisão: a gestão penal da pobreza agrária no Brasil

Na Europa e em outras partes do mundo, o processo de urbanização decorreu da criação de amplo mercado de trabalho nas cidades, tão amplo que foi capaz de assimilar o excedente populacional proveniente do campo. Já no Brasil, isto não ocorreu: o crescimento da população urbana não ocorreu concomitantemente com o aumento do emprego (FURTADO, 2006). Faltou emprego, e boa parte da população teve de se contentar com subempregos e habitações precárias.

A questão que move este estudo é: como se desenvolveu o processo de criminalização e segregação do pobre no espaço temporal que vai da transformação urbana e industrial do Brasil à atualidade? A hipótese que se levanta é a de que, em razão de condições estruturais do sistema, o esvaziamento do campo, juntamente com a queda do potencial de absorção dos migrantes nas cidades-destino, foram condições genéticas das periferias urbanas, onde as camadas urbanas pauperizadas se concentraram e continuam segregadas e marginalizadas. Em continuidade, propõe-se que os pobres urbanos segregados nas periferias são objeto de um processo de criminalização que implica na estigmatização do pobre e, mais recentemente, em tentativas de controle social desta população, que vê crescer um Estado Penal onde jamais esteve presente um Estado implementador de direitos.

A perspectiva adotada é interdisciplinar, na medida em que conjuga um estudo da Geografia Crítica de Milton Santos (1993), o qual fundamenta nossas compreensões sobre os temas da conformação socioespacial brasileira, da urbanização e da mobilidade urbana e um estudo Criminológico da gestão penal da pobreza, a partir da Criminologia Crítica, baseada, principalmente, em estudos de Michel Foucault, Juarez Cirino e Loïc Wacquant.

Assim, pretende-se tracejar o caminho da população pobre do campo, que inicia com a história da configuração da detenção da terra e do poder socioeconômico, perpassa pelo processo de industrialização e urbanização que teve lugar no século XX e deságua no surgimento das periferias urbanas. Em seguida, delinear a forma pela qual a população marginalizada das cidades é vista pela sociedade e gerenciada pelo Estado, após as rápidas transformações que transformaram o Brasil em um país urbano.

\section{QUESTÃO AGRÁRIA E EXCLUSÃO DO CAMPO}

A história da questão agrária no Brasil é uma representação de como as configurações de detenção da terra e do poder socioeconômico transformaram-se sem 
mudar a sua essência, sofreram "reformas" caracterizadas mais por permanências do que por rupturas, sendo por isto chamadas conservadoras. É uma demonstração de como a grande propriedade soube se reinventar e permanecer como uma característica da conformação socioeconômica e territorial do país, rejeitando-se todas as propostas de adoção de um modelo de agricultura familiar em médias propriedades (mais vantajoso em termos de distribuição de riqueza e de mão-de-obra).

Desde o período das sesmarias, perpassando pelas disposições da Lei de Terras, de 1850, pela adoção do modelo de colonização de Torrens e Wakefield e pela escolha da linha prussiana de colonização, é notada uma tendência à formação de latifúndios (exploração predatória e extensiva) no Brasil.

Estas características de apropriação do espaço perduraram, embora em alguns momentos tenham existido chances de modificar o status quo, como, por exemplo, durante o longo Governo Vargas, durante o qual se delineou a questão agrária no Brasil ${ }^{2}$. Neste momento, verificou-se a primeira grande chance de enfrentamento das oligarquias agrárias dependentes da plantation, com a crise de 1929. No entanto, nem Vargas, nem os governos seguintes, optaram por mudar a configuração fundiária brasileira.

Juscelino Kubitschek, por exemplo, optou pela permanência da política varguista para o campo. O então Presidente optou por ignorar as reivindicações pela reforma agrária, bastante presentes em seu governo, e "gerenciar" tal questão incentivando a Marcha para o Oeste iniciada por Getúlio 3 .

Um certo continuísmo ocorreu também na Ditadura Militar, pois as "mudanças" implementadas, através do Estatuto da Terra, nada mais significaram senão a modernização do latifúndio, com a expulsão do trabalhador do campo, que passou a ocupar a periferia das grandes e médias cidades ou a trabalhar como boia-fria (MEDEIROS, 2010) ${ }^{4}$.

O modelo de política agrária estabelecido pelo Governo Militar permanece vigente (BUAINAIN, 2008), em grande parte. Além disso, esta configuração tomou contornos aparentemente irreversíveis, com a formação do Complexo Agroindustrial ${ }^{5}$.

Percebe-se, portanto, que na história brasileira o campo sempre foi o lugar da grande propriedade, desde a escolha política deliberada da colonização via prussiana até a adoção da política do agronegócio nos anos 2000. Essa característica da 
Da exclusão do campo à inclusão na prisão: a gestão penal da pobreza agrária no Brasil

configuração terreal brasileira trouxe e traz consequências enormes, quando consideradas as mudanças localizadas do século XX.

A partir dos anos 1990, os governos brasileiros adotaram o projeto político neoliberal, segundo as diretrizes do Fundo Monetário Internacional (FMI), do Banco Mundial (BM) e do Consenso de Washington ${ }^{6}$, o que implicou muitas consequências sociais, como a desresponsabilização do Estado quanto à garantia dos direitos sociais, pois, nesta perspectiva, “[...] o desenvolvimento social era visto como resultado do crescimento econômico" (REIS et al., 2007, p, 366-371).

Com efeito, a década de 1990 caracterizou-se não apenas por uma adequação da política brasileira aos interesses do capitalismo neoliberal em âmbito mundial, mas também pela deficiente política pública de consecução da reforma agrária, pela crise da agricultura familiar, pela estagnação econômica e ainda pela mecanização de cadeias relevantes do agronegócio, que expulsou muitos trabalhadores do campo (BUAINAIN, 2008, p. 38). Este projeto neoliberal continua em plena consecução pelos governos recentes, desde a década de 1990 até o ano de elaboração do presente estudo.

Com o esvaziamento da zona rural ocorrido em meados do século XX, a periferia das cidades funcionou como porta de entrada para os excluídos do campo. A expressão "excluídos do campo" referem-se àqueles que não lograram permanecer na zona rural quando a mecanização e a formação do Complexo Agroindustrial (CAI) se apropriaram deste ambiente, expulsando trabalhadores empregados, bem como pequenos produtores. "Excluídos do campo" designa toda uma população que, em razão das características fundiárias do país, já podiam ser consideradas excluídas, e que terminaram por sê-lo, definitivamente, quando o latifúndio se uniu ao grande capital.

\section{MIGRAÇÃO DO TIPO RURAL-URBANA E A TRANSFERÊNCIA DA POBREZA RURAL PARA O AMBIENTE URBANO: A FORMAÇÃO DA DESIGUALDADE SOCIAL NO CAMPO E NAS CIDADES}

O Século XX foi o palco de profundas transformações nas relações entre os espaços rural e urbano. O campo da segunda metade do século passado repeliu os seus pobres para as cidades; as cidades os aceitaram a contragosto. O fato de que não há empregos para todos é o ponto nodal da crise urbana após a modernização conservadora do campo e a formação do Complexo Agroindustrial. 
Nas décadas de 1950 a 1960, o campo foi tomado pelo processo de modernização conservadora. Braços tornaram-se desnecessários, pois o que se queria produzir eram commodities para exportação, em grande escala. Não havia mais lugar para o parceiro, para o meeiro, o vaqueiro. Só restou caminharem para as cidades.

Novas relações se estabeleceram. O campo e a cidade se tornaram espaços dinâmicos e interdependentes. O mercado nacional se fortaleceu, o território nacional se tornou mais acessível de norte a sul com a expansão das estradas e dos transportes. Este panorama parece encantador se não for visto de perto com uma boa lente de aumento.

Por detrás do processo de industrialização e urbanização, que emergiram da necessidade de redistribuir, no espaço, recursos humanos no mercado de trabalho, estava a marginalização e o empobrecimento da população. Formaram-se grandes bolsões de miséria nas grandes cidades e ampliou-se o trabalho precário (como o dos boias-frias), como consequências da transferência da pobreza rural para as áreas periféricas da cidade e do surgimento do desemprego estrutural.

Em outras palavras, a questão agrária tornou-se também uma questão urbana, na medida em que a configuração fundiária brasileira impeliu o êxodo rural para as cidades e estas foram incapazes de absorver a mão-de-obra excedente. Inexistindo empregos para todos, uma extensa massa de pessoas pauperizadas passou a viver nas zonas periféricas, nas décadas de 1960 e 1970, sustentando a si próprias e às suas famílias por meio do subemprego e do emprego precário ${ }^{7}$.

A facilitação dos transportes, a redução da mortalidade, o incremento da concentração fundiária ${ }^{8}$, e as relações arcaicas de trabalho existentes em determinadas regiões do país foram os principais motivos do êxodo rural, que ocorreu mais forte onde foi mais intensa a modernização. Para o Estado, à luz da política governamental da época - que propugnava uma complementaridade entre as atividades produtivas tratava-se de um movimento indicativo de progresso 9 .

Como ensina Silva, “[...] ao modernizar-se, o setor agrícola tornava-se um consumidor de insumos urbanos, aumentava a produtividade e liberava força de trabalho para as grandes metrópoles" (SILVA, 2008, p. 26) ${ }^{10}$. No entanto, não foi o que ocorreu a longo prazo, pois na verdade o crescimento econômico proveniente do incremento da produtividade no campo não importou em melhorias na distribuição de renda; pelo contrário, ocorreu um aprofundamento da pobreza nos centros urbanos. 
Da exclusão do campo à inclusão na prisão: a gestão penal da pobreza agrária no Brasil

Durante a década de 1960, o acesso ao emprego não era difícil e os fenômenos migratórios não eram vistos como problema. Já na década de 1970 ocorreu um arrefecimento no crescimento econômico, com aumento da pobreza urbana A indústria não se mostrou capaz de absorver novos contingentes de migrantes, as periferias da cidade aumentaram e formaram-se as favelas. A migração tornou-se, finalmente, um problema urbano (SILVA, 2008).

Não foi apenas em São Paulo (exemplo mais conhecido) que este processo ocorreu. Em todo o Sudeste a urbanização e a metropolização ocorreram com grande força nas décadas de 1960 e 1970. Conforme Dadalto e Rodrigues (2015), no Espírito Santo, até 1950, 78,2\% da população era rural; a partir da década de 1970, os Municípios que compõem a Grande Vitória passaram a concentrar quase metade da população do estado, sendo que nesta época a concentração de pessoas não naturais era de $46,7 \%$.

Os efeitos colaterais do esvaziamento do campo e da ocupação desenfreada das cidades foram sentidos com grande força após a década de 1980, com a redução da oferta de emprego, em especial no setor industrial, a piora na distribuição de renda e a ocorrência de surtos inflacionários.

De 1990 aos anos 2000, impôs-se um novo padrão migratório, caracterizado pela perda de força atrativa das metrópoles - embora se reforcem e permaneçam as periferias urbanas -, pela tendência de crescimento das cidades médias e a diminuição da migração interestadual, ao passo que aumentou a migração de retorno (SILVA, 2008). Santos (1993) enxerga o aumento das cidades médias e a perda de força atrativa das metrópoles não como uma diminuição do movimento urbanizador ou mesmo como desmetropolização, mas como a expansão da metrópole por meio de um processo de ajustamento derivado da expansão e crise do mercado.

Concorda-se com Santos (1993) no sentido de que houve uma expansão das metrópoles, e não uma desmetropolização. As cidades de tamanho médio cresceram aceleradamente. Também houve crescimento da extrema pobreza nos domicílios urbanos entre 1980 e 2002 como consequências dos fluxos migratórios e da incapacidade de absorção dos imigrantes no mercado de trabalho (CUNHA, 2009).

A transferência da pobreza rural para o ambiente urbano foi um dos efeitos próprios das contradições do capitalismo no Brasil. Os limites para integração da população migrante, o desemprego da população marginal que vive nas áreas periféricas 
e do mercado informal, ou pendulando entre o mercado formal e o informal, geram preocupação na medida em que as cidades continuam a sofrer um processo de expansão da metrópole e dos problemas urbanos que ela arrasta consigo.

\section{A GESTÃo PENAL dA POBREZA AgrÁria NO BRASIL: UMA ABORDAGEM A PARTIR DA CRIMINOLOGIA CRÍTICA}

Michel Foucault (2004), ao estudar a história da sujeição do corpo ao sistema penal, na Modernidade, apontou para o fato de que, desde o surgimento do Estado Moderno, o ajuste dos mecanismos de poder resultou em uma vigilância mais efetiva e atenta do corpo social, por meio de uma economia do poder.

Ele localizou a mudança na forma de punir, no século XVIII, na teorização em torno da propriedade e do contrato social, necessária para a implementação da nova economia do poder, que permitiria atingir a todos e a cada um, na medida em que todos concordavam com o pacto social e com a sua não violação.

Assim, formou-se uma sociedade disciplinar, que, por meio da disciplina dos exércitos, das escolas e dos hospitais, uma sociedade na qual cada indivíduo seria uma peça, um corpo dócil, um corpo adestrado. Essa sociedade, no entanto, só funciona se existir uma vigilância hierárquica, e um mecanismo penal.

No interior desse mecanismo de disciplina-punição, está o delinquente. $\mathrm{O}$ delinquente não é o infrator, o delinquente distingue-se do infrator por ser responsável pelo seu ato (pois possui vontade livre e consciente) e porque o ato praticado revela seus instintos, suas tendências, seu temperamento, sua "alma"; assim, o delinquente é o sujeito fabricado pela ciência penitenciária (FOUCAULT, 2004).

Foucault observa que, neste sistema disciplinar, a prisão se generalizou e, embora seja um sistema ineficaz para os seus propósitos declarados, pois “[...] as prisões não diminuem a taxa de criminalidade" (FOUCAULT, 2004), estranhamente ela não foi substituída como método de punição. A partir desta constatação, ele sugere a inversão do problema e pergunta para que objetivo o fracasso dessa instituição é útil. Eis a resposta encontrada: "a prisão é destinada a distinguir as infrações, a organizar a transgressão das leis, gerir as ilegalidades, diferencialmente, a depender da classe social" (FOUCAULT, 2004, p. 226-227). Acrescenta que na verdade "a prisão conseguiu o seu objetivo, o de produzir o delinquente, que é o ser infrator controlado pelo sistema disciplinar" (FOUCAULT, 2004, p. 231). 
Da exclusão do campo à inclusão na prisão: a gestão penal da pobreza agrária no Brasil

A Criminologia Crítica enxerga este indivíduo "delinquente", inserido em uma sociedade disciplinar, a partir da sua posição na estrutura social (divisão de classes). Por este ponto de vista, o "criminoso" ou "delinquente" é visto como o bode expiatório do sistema capitalista, objeto da agressão das classes inferiores e das classes médias, que desviam para ele as insatisfações em relação às classes superiores. Esta abordagem acerca do indivíduo submetido ao mecanismo penal da sociedade disciplinar contrasta com diversas teorias denominadas sob o rótulo geral de "positivistas", pois estas procuram apresentar o crime como escolha racional e consciente do delinquente e este último como individualmente responsável por seus atos.

O ponto nodal que diferencia as teorias positivistas e as abordagens críticas do delito e do delinquente é que a primeira se esquiva de enfrentar o seu conteúdo ideológico ou a significação política e as questões de interesse material e de poder subjacentes. Para as teorias positivistas, os sistemas jurídico e político do Estado são instituições racionais que visam ao bem comum, sendo que a estrutura econômica é entendida como organização racional do trabalho. Ensina Juarez Cirino que "[...] o postulado ideológico básico exprime uma visão consensual do mundo, livre de contradições de classes, das lutas econômicas e políticas das classes articuladas no modo de produção dominante" (SANTOS, 1984, p. 23). A Criminologia Crítica rejeita estas premissas porque combate a afirmação da autodeterminação racional, já que entende ser o comportamento criminoso explicado pelas condições materiais da vida social (SANTOS, 1979).

Um dos sociólogos que enfrenta mais recentemente a questão criminal é o francês Loïc Wacquant. Ele pesquisou o fenômeno do grande encarceramento do século XX em concatenação com a difusão do modelo neoliberal no âmbito mundial.

A partir de uma análise do modelo neoliberal instalado nos Estados Unidos a partir dos governos Nixon e Reagan, Loïc Wacquant observou que a nova gestão da miséria se faz por meio do encarceramento em massa; se, no passado, a prisão serviu para regular a mão-de-obra disponível (conforme Rusche e Kirchheimer) e para disciplinar o trabalhador em um regime industrial (conforme Melossi e Pavarini), no final do século XX e século XXI ela serve a um só objetivo: gerir a miséria e eliminar os pobres. Neste ponto, a análise de Wacquant se aproxima à de Foucault, pois se verifica que ambos dão ao sistema criminal, sobretudo à pena, a mesma finalidade: produzir o infrator controlado pelo sistema (ou seja, o delinquente); não se trata de 
objetivos ressocializantes $^{11}$, mas apenas de gestão. Por estes vieses, o sistema repressivo não faliu em seus objetivos, ele segue realizando-os.

De acordo com Wacquant, nos Estados Unidos, a crise do Estado de BemEstar Social $^{12}$ levou à substituição por um Estado penal e policial. No novo sistema econômico transnacionalizado, não existe espaço para todos trabalharem, e a resposta para isto é o encarceramento em massa. A partir do governo Reagan (1980), afirma Wacquant que "[...] a guerra contra a pobreza foi substituída pela guerra contra os pobres" (WACQUANT, 2003, p. 23-24), com a diminuição dos recursos justamente para os programas sociais destinados à classe mais pobre, e a ampliação da malha disciplinar do Estado (WACQUANT, 2003).

Em suma, a tese do autor é no sentido de ter sido feita uma redefinição radical da missão do Estado, que, em vez de responsabilizar-se pela concretização dos direitos sociais, trata destes como questão criminal, centrando a contenção da pobreza nos recursos endereçados ao sistema criminal.

A semelhança do quadro pintado por Wacquant com o cenário brasileiro não é mera coincidência. O Brasil não teve um real Estado de Bem-Estar Social, diferentemente dos Estados Unidos. A urbanização, a modernização e a exclusão do campo no Brasil ocorreram de maneira acelerada, principalmente na segunda metade do século XX, sem que o mercado pudesse absorver o quantitativo de pessoas que deixavam o campo. A exclusão do campo foi um fator de desemprego e de aumento da pobreza urbana, em um país onde os direitos sociais foram pouco implementados.

Wacquant (2001) qualifica a pobreza do mundo da era pós-keynesiana como produto não só da falta de trabalho, mas da fartura de trabalho temporário, mal pago e também da concentração da pobreza urbana em territórios desconectados das economias nacionais. Ele extrai tais conclusões dos estudos da banlieue francesa e do gueto estadunidense, mas certamente podem ser aplicadas às favelas brasileiras, pois isto nada mais é que a tradução das contradições da ordem capitalista mundial vigente, que o Brasil integra em uma posição de país subdesenvolvido; esta é a descrição daquilo que o autor chama da marginalidade avançada, termo que indica a marginalidade não como oriunda do atraso, mas dos setores mais avançados da economia ${ }^{13}$.

O Brasil modernizou-se tardiamente e muito rapidamente assistiu à expansão da metrópole, à formação de favelas e ao incremento da pobreza urbana, a partir da transferência da pobreza rural (exclusão do campo) para o ambiente citadino. 
Da exclusão do campo à inclusão na prisão: a gestão penal da pobreza agrária no Brasil

Enquanto a Europa e os Estados Unidos sofreram tal processo ao longo de muitos anos, o Brasil se incluiu nele rapidamente, impelido pelos arranques "progressistas" da modernização conservadora.

O problema central de todo este processo está nas características da estrutura socioeconômica existente, não modificada, mas perpetuada, por estes processos de mudança, a qual (a) desestimula a permanência no campo, impelindo os seus habitantes para as cidades, onde não encontrarão trabalho formal, pois uma das características da marginalidade avançada é justamente o trabalho fragmentado, precário e inseguro (WACQUANT, 2001, p. 167); (b) com isso, há uma transferência dos pobres rurais para as cidades, bem como aumento das periferias e favelas, outra característica da marginalidade avançada, qual, seja, a fixação e estigmatização territoriais (WACQUANT, 2001, p. 168) ${ }^{14}$; (c) concentram-se cada vez mais recursos nas mãos de poucos - como, por exemplo, nas mãos dos grandes produtores da agroindústria e dos setores financeiros; (d) faz avançar o desemprego estrutural.

A gestão da pobreza agrária, neste contexto, se fez com o direcionamento do pobre do campo para a cidade, sem que houvesse condições de incorporação ao ambiente receptor, por meio do trabalho e da inclusão social, com acesso a direitos básicos tais como à habitação digna, saúde e educação. A pobreza agrária transmudouse em pobreza urbana; com as migrações e a urbanização, aumentou a competitividade pelo emprego formal, cresceram as zonas periféricas das cidades e aumentou o emprego informal.

Para a solução do problema do crescimento da violência urbana, aposta-se cada vez mais na penalização como forma de prevenção e contenção da criminalidade crescente e cada vez menos na realização dos direitos sociais, ou seja, no tratamento da insegurança social como mera insegurança física. O Estado Penal e a sua ideologia implícita de responsabilizar os pobres por seus próprios problemas oferecem uma desculpa para o desregramento da economia e a redução da proteção social, o que os torna alvos mais fáceis dos processos de criminalização. É contra isto que Wacquant e a Criminologia Crítica se posicionam, o tratamento de questões sociais não resolvidas como questões criminais.

As teorias positivistas e de defesa social foram historicamente acolhidas no Brasil pela elite intelectual, como consequência de um passado excludente e desigual, que buscava justificativas para sustentar a desigualdade e a exclusão de determinados 
grupos sociais. Em um breve retorno ao passado, é possível vislumbrar a incorporação destas ideias no Brasil dos séculos XIX e $\mathrm{XX}^{1516}$. Embora mais recentemente os intelectuais brasileiros afetos à questão criminal já tenham despertado para as falácias destes discursos, os mesmos permanecem com força na sociedade, inclusive no seio das classes para as quais eles se dirigem (SANTOS, 2015).

Os sintomas da inclusão brasileira na lógica do Estado Penal são facilmente perceptíveis ao se observar o crescimento vertiginoso da população carcerária no Brasil. De 2005 a 2012, a população carcerária quase dobrou: passou e 296.919 presos para 515.482 presos (BRASIL, 2015). Esta população carcerária é altamente selecionada: Santos (2015, p. 460) aponta que, em 2009, somente 1.715 presos possuíam nível superior completo, e somente 60 possuíam nível maior que o superior; por outro lado, a maioria esmagadora de 178.540 presos possuíam o nível fundamental incompleto, 49.521 eram alfabetizados, apenas, e 26.091 eram analfabetos.

Outros sintomas podem ser apontados, tais como o aumento vertiginoso da segurança privada no Brasil, decorrente de um medo difuso da criminalidade cada vez mais alastrado na sociedade - como aponta José Vicente Tavares dos Santos (2004) em relação às sociedades da modernidade tardia - e o incremento dos gastos públicos com a segurança pública.

Assim, com um Estado social mínimo e um Estado Penal a pleno vapor, a justiça criminal funciona como mais um fator de solapamento dos pobres, já que estes são estigmatizados em razão da pobreza e da moradia em áreas periféricas das cidades, vistos como seres dignos de desconfiança, pelas classes média e alta, e criminalizados como decorrência da forte crença, no Brasil, de que há uma relação direta entre pobreza e criminalidade ${ }^{17}$.

\section{CONSIDERAÇÕES FINAIS}

No Brasil, a origem da pobreza urbana pode ser localizada no período de aceleramento do processo de urbanização, industrialização e exclusão do campo, especialmente a partir da década de 1960. A zona rural acomodava, até então, grandes contingentes populacionais que, embora não possuíssem terras (meios de produção) tinham o seu lugar na produção, seja como parceiro, como meeiro, ou mesmo como empregado. 
Da exclusão do campo à inclusão na prisão: a gestão penal da pobreza agrária no Brasil

Essas pessoas, embora estivessem acomodadas no campo até então, já podiam ser qualificadas como "excluídas do campo", já que no Brasil prosperou uma conformação territorial firmada no grande latifúndio; assim, de certa forma, os parceiros, meeiros e empregados rurais estavam incluídos precariamente na economia rural, pois não possuíam como própria o fator produtivo "terra". Não obstante, muitos deles permaneciam por anos a fio, até vidas e gerações inteiras, no mesmo lugar e na mesma função.

Porém, a exclusão do campo se completou quando o latifúndio se transmudou em Complexo Agroindustrial: muitas ocupações no campo foram extintas com a modernização conservadora, impelindo os trabalhadores rurais para as cidades. Ao mesmo tempo, os pequenos produtores que não conseguiram incluir-se nas novas tecnologias de produção não tiveram alternativa senão ceder ao latifúndio mecanizado.

Em um primeiro momento (décadas de 1950 e 1960), a exclusão do campo atendeu às necessidades do Capital, pois o processo de rápida industrialização necessitava dessa mão de obra excedente vinda do campo. Contudo, logo este ímpeto arrefeceu, e cada vez mais difícil foi se tornando a inclusão do emigrante do campo nas engrenagens do trabalho fabril nas cidades.

A década de 1970 sentiu os primeiros impactos da diminuição do crescimento econômico, mas foi na década de 1980 (a década perdida) que os índices de crescimento econômico decresceram e aumentou a pobreza urbana. Ocorreu, na verdade, uma transferência da pobreza rural para a zona urbana e o aumento da pauperização nas cidades. Os efeitos colaterais do esvaziamento do campo e da ocupação desenfreada das cidades foram sentidos com grande força após a década de 1980, com a redução da oferta de emprego, em especial no setor industrial, a piora na distribuição de renda e a ocorrência de surtos inflacionários.

As periferias da cidade aumentaram e os seus integrantes passaram a ser identificados como causadores dos problemas sociais. Formaram-se comunidades à parte do sistema jurídico-econômico oficial, ou seja, favelas, com um ordenamento interno próprio e muitas vezes contrário ao ordenamento jurídico vigente, conforme descortinou Boaventura de Sousa Santos em um estudo realizado em uma favela do Rio de Janeiro (1980).

A partir da década de 1990, com a adoção de um projeto político neoliberal no Brasil, houve a definitiva aceitação da pobreza como uma consequência das 
contradições estruturais do sistema e uma paulatina desresponsabilização do Estado quanto ao fornecimento de direitos básicos para os cidadãos. A adoção oficial de políticas de Estado mínimo nada mais é do que a assunção de uma consequência inevitável do "desenvolvimento capitalista" no âmbito mundial: a cisão da sociedade em uma classe de cidadãos, trabalhadores empregados e consumidores no mercado, e de uma classe de não cidadãos, favelados, trabalhadores ocasionais, integrantes do lumpemproletariado.

Esta configuração mostrou-se persistente e quase que inevitável, pois decorre das contradições intrínsecas ao desenvolvimento do capitalismo no mundo. Modificaram-se as relações de emprego, elas tornaram-se temporárias, precárias, sem qualquer garantia acerca do amanhã. O campo tornou-se incapaz de gerar novos postos de trabalho ${ }^{18}$. Os pobres foram enclausurados nas grades das periferias e favelas, locais que sofrem de estigmatização territorial.

Mas a pior e mais danosa consequência de todo este processo de concentração da pobreza nas cidades e de aumento do desemprego ainda não foi citada: o gerenciamento da pobreza passou a ser feito por meio da penalização, e não da realização dos direitos sociais. A insegurança social causada por todas estas mudanças foi imputada à responsabilidade individual dos pobres: configurou-se um Estado Penal cuja ideologia fundante é a de responsabilizar os pobres por seus próprios problemas, oferecendo uma desculpa para o desregramento da economia e a redução da proteção social.

Por todo o exposto, é possível visualizar uma intersecção entre a questão agrária e o despovoamento do campo e a questão criminal, que empurra para as grades das prisões a população pauperizada das cidades. Esta reflexão nos traz panoramas para pensar políticas públicas de enfrentamento da pobreza e da marginalidade avançada (WACQUANT, 2011), bem como para enfrentar as questões criminais no Brasil.

A partir deste estudo, pode-se perceber que o incentivo de políticas de permanência no campo (e de distribuição fundiária) é um dos aspectos que poderiam diminuir o desemprego estrutural e a marginalização de pessoas nas grandes cidades; no entanto, dado o avançado fenômeno da mecanização do latifúndio, sobram poucas esperanças de que isto se realize.

Portanto, qual é a utilidade de se fazer um estudo da criminalização dos pobres e da formação do Estado Penal envolvendo a questão agrária? Podemos pensar 
Da exclusão do campo à inclusão na prisão: a gestão penal da pobreza agrária no Brasil

em várias razões. Em primeiro lugar, a conscientização sobre os problemas históricos do Brasil (concentração de renda, concentração fundiária, formação de periferias urbanas, impacto dos movimentos migratórios, etc.) é um campo frutífero para novas ideias sobre a implementação de políticas públicas para o contorno e superação destes problemas. Em continuidade, e acreditamos que este seja o principal motivo/utilidade de um estudo como este, é demonstrar como e de que forma se originaram os "favelados", a população marginalizada e estigmatizada, e destacar a complexidade deste processo e porque ele que não decorre unicamente de escolhas pessoais e individuais, mas de algo muito maior que é a conformação do capitalismo no âmbito mundial e nacional.

Ademais, existe um ressentimento de um estudo criminológico sobre temas agrários, já que a Ciência Agrária é complexa e reclama uma abordagem multi e interdisciplinar, assim como a Criminologia (CARDOSO, 2012). O panorama agrário da realidade brasileira tem muito que ver com a construção de áreas marginais, o espraiamento da pobreza e o desemprego estrutural que atinge milhões de brasileiros; por isso, pode-se dizer que é um fator a mais a considerar quando se fala em Estado Penal.

Lado outro, pensar sobre a instalação de um Estado Penal no Brasil é pensar nos pobres diuturnamente alvos de processos de criminalização e mudar o viés que os enxerga a partir da responsabilidade individual para começar a vê-los como cidadãos excluídos do acesso a direitos básicos e incluídos em um Estado que valoriza a punição e a estigmatização. Trocar esta lente é um grande passo para enxergá-los como alguém que merece respeito; é passar a ver como o sistema punitivo brasileiro é seletivo ao punir majoritariamente os pobres e deixar incólumes os ricos; é conjugar direito penal e direitos humanos para verificar uma necessidade premente de frear o ímpeto punitivista do Estado.

\section{REFERÊNCIAS}

ALVAREZ, Marcos César; SALLA, Fernando; SOUZA, Luís Antônio F. A sociedade e a Lei: o Código Penal de 1890 e as novas tendências penais na Primeira República. Justiça e História: Porto Alegre, v. 3, n. 6, 2003. Disponível em:<http://bdjur.stj.jus.br/jspui/bitstream/2011/66122>. Acesso em: 6 fev. 2017.

BRASIL. Mapa do Encarceramento: os Jovens do Brasil. 2015. Disponível em: < http://juventude.gov.br/articles/0009/3230/mapa-encarceramento-jovens.pdf >. Acesso em: 10 ago. 2017. 
BUAINAIN, Antônio Márcio (Org.). Luta pela terra, reforma agrária e gestão de conflitos no Brasil. Campinas: Editora UNICAMP, 2008.

CARDOSO, Franciele Silva. A luta e a lida: estudo do controle social do MST nos acampamentos e assentamentos de Reforma Agrária. 2012. (Tese de Doutorado em Direito). Universidade de São Paulo, 2012.

CUNHA, Marina Silva da. Desigualdade e pobreza nos domicílios rurais e urbanos no Brasil, 1981-2005. Revista econômica do Nordeste, vol. 40, n. 1., jan-mar. 2009. Disponível em: < https://www.bnb.gov.br/projwebren/Exec/artigoRenPDF.aspx?cd_artigo_ren=1113>. Acesso em: 04 ago. 2017.

DADALTO, Maria Cristina; RODRIGUES, Márcia Barros Ferreira. Migração e violência: criminalização e violência criminalizada. Revista Internacional de História Política e Cultura Jurídica. Rio de Janeiro: vol. 7, nº 2, maio-agosto, 2015.

DELGADO, Guilherme Costa. Do capital financeiro na agricultura à economia do agronegócio: mudanças cíclicas em meio século (1965-2012). Porto Alegre: Editora da UFRGS, 2012.

DEL OLMO, Rosa. A América Latina e sua Criminologia. Rio de Janeiro: Editora Revan, 2004.

FILGUEIRAS, Luiz. O neoliberalismo no Brasil: estrutura, dinâmica e ajuste do modelo econômico. En publicación: Neoliberalismo y sectores dominantes. Tendencias globales y experiencias nacionales. Basualdo, Eduardo M.; Arceo, Enrique. CLACSO, Consejo Latinoamericano de Ciencias Sociales: Buenos Aires, 2006. Disponível em: <http://biblioteca.clacso.edu.ar/ar/libros/grupos/basua/C05Filgueiras.pdf>. Acesso em: 6 abr. 2017.

FOUCAULT, Michel. Vigiar e punir. Petrópolis: Editora Vozes, 2004.

FURTADO, Celso. O Brasil do Século XX. In: IBGE. Estatísticas do Século XX. Rio de Janeiro: Instituto Brasileiro de Geografia e Estatística, 2006.

HAAS, Jaqueline Mallmann; HILLIG, Clayon Hillig. A abordagem da pobreza rural no contexto das novas ruralidades. $48^{\circ}$ Congresso SOBER. Disponível em <http://www.sober.org.br/palestra/15/94.pdf>. Acesso em: 04 ago. 2017.

LINHARES, Maria Yedda \& SILVA, Francisco Carlos Teixeira. Terra prometida: uma história da questão agrária no Brasil. Rio de Janeiro: Campus, 1999.

MEDEIROS, Leonilde Servolo. Movimentos sociais no campo, lutas por direitos e reforma agrária na segunda metade do século XX. In.: CARTER, Miguel (Org.). Combatendo a desigualdade social: o MST e a reforma agrária no Brasil. São Paulo: Editora UNESP, 2010, p. 113-136. 
Da exclusão do campo à inclusão na prisão: a gestão penal da pobreza agrária no Brasil

MOREIRA, Vânia Maria Losada. Os anos JK: industrialização e modelo oligárquico de desenvolvimento. In: FERREIRA, Jorge \& DELGADO, Lucília de Almeida Neves (Orgs.). O Brasil Republicano: O tempo da experiência democrática - da democratização de 1945 ao golpe civil-militar de 1964. Rio de Janeiro: Civilização Brasileira, 2003.

REIS, Carlos Nelson dos; PINHEIRO, Lessi; RIBEIRO, Letícia; OLIVEIRA, Mara. Ajuste Fiscal e Gastos Sociais no Brasil: a estabilidade em detrimento da equidade a partir das influências do FMI e Banco Mundial. Observatório Iberoamericano Del dessarrollo local y La economia social. Málaga: 2007, p. 352-381. Disponível em <http://repositorio.pucrs.br/dspace/handle/10923/7945>. Acesso em: 6 abr. 2017.

SANTOS, Bartira Macedo de Miranda. Defesa Social e Segurança Pública: desafios para a implantação de políticas públicas de segurança no Brasil. 2015. (Relatório de Pesquisa de Pós-Doutorado). Pontifícia Universidade de Goiás, Goiânia, 2015.

SANTOS, Boaventura de Sousa. Notas sobre a História Jurídico- Social de Pasárgada. In: SOUTO, Cláudio; FALCÃO, Joaquim (Org.). Sociologia e direito: textos básicos de sociologia jurídica. $1^{a}$ ed. São Paulo: Pioneira, 1980, p. 109-117. Disponível em < http://www.geocities.ws/b3centaurus/livros/s/boavpassar.pdf > Acesso em 09 ago. 2017.

SANTOS, José Vicente Tavares dos. Violências e Dilemas do Controle Social nas sociedades da modernidade tardia. São Paulo em Perspectiva, 18 (1): pág. 3-12, 2004. Disponível em < http://www.scielo.br/pdf/spp/v18n1/22221.pdf>. Consultado em: 20 ago. 2017.

SANTOS, Juarez Cirino dos. A criminologia da repressão: uma crítica ao positivismo em criminologia. Rio de Janeiro: Forense, 1979.

As raízes do crime: um estudo sobre as estruturas e as instituições da violência. Rio de Janeiro: Forense, 1984.

SANTOS, Milton. A urbanização brasileira. São Paulo, Editora Hucitec, 1993.

SILVA, Uvanderson Vítor da. Velhos caminhos, novos destinos: Migrante nordestino na Região Metropolitana de São Paulo. 2008. (Dissertação de Mestrado em Sociologia). Universidade de São Paulo, 2008.

WACQUANT, Loïc. Punir os pobres: a nova gestão da miséria nos Estados Unidos. Rio de Janeiro: F. Bastos, 2001, Revan, 2003.

. A segurança criminal como espetáculo para ocultar a insegurança social: entrevista com Loïc Wacquant. Fractal, Revista de Psicologia, vol. 20, n 1, Rio de Janeiro, 2008. Entrevista concedida a Fernandas Bocco, Maria Lívia Nascimento e Cecília Coimbra. Disponível em < http://bases.bireme.br/>. Consultado em: 09 ago. 2017.

Os condenados da cidade: estudo sobre marginalidade avançada. Rio de Janeiro: Revan, 2001. 


\begin{abstract}
${ }^{1}$ Entre 1940 e 1960, o aumento anual da população urbana era menor que o da população rural. Entre 1960 e 1970, os números se aproximaram; já entre 1970 e 1980, o crescimento da população urbana superou o da população rural (SANTOS, 1993, p. 30)
\end{abstract}

${ }^{2}$ Foi na Era Vargas que se apresentou uma questão agrária no Brasil (LINHARES; TEIXEIRA, 1999 , p. 125), pois em seu governo o campo ganhou um lugar no desenvolvimento nacional. Até então, diante da ausência da indústria, o campo era a única possibilidade, a única "vocação" do país. Ocorre que, neste período, o campo passou a participar do desenvolvimento nacional, mas não houve um enfrentamento direto dos poderes das oligarquias: não se realizou a reforma agrária, nem se estendeu aos trabalhadores rurais os direitos concedidos aos urbanos. Propositalmente, Vargas propôs a ocupação das fronteiras no Oeste, mas evitou conflitos com os latifúndios estabelecidos em áreas consolidadas.

${ }^{3}$ De acordo com Moreira (2003), Kubistchek evitou tomar partido em qualquer política agrária, ignorando a ampliação dos conflitos agrários e o crescimento dos movimentos sociais, como as Ligas Camponesas e a politização no campo.

${ }^{4}$ A proposta de reforma agrária que prevaleceu no seio do regime militar - dentro do qual, vale dizer, havia divergências - foi a de modernizar o latifúndio e colonizar espaços vazios, por isso o lançamento de vários projetos neste sentido (BUAINAIN, 2008, p. 31).

5 Segundo Delgado (2012, p. 77), houve um período de transição entre a política de modernização conservadora do campo da era militar, em meados da década de 1980 e 1990, e a economia do agronegócio, adotada a partir dos anos 2000. A economia do agronegócio, no Brasil, segundo Delgado (ibidem, p. 94), "na acepção brasileira do termo é uma associação do grande capital agroindustrial com a grande propriedade fundiária", que persegue o lucro e a renda da terra "sob o patrocínio de políticas de Estado".

${ }^{6}$ Se na década de 1980, apesar da crise do capitalismo no mundo, ainda persistia uma tentativa de redefinir o modelo de substituição de importações, "mantendo-se ainda um papel fundamental para o Estado no processo de acumulação e desenvolvimento" (FILGUEIRAS, 2006, p. 181-182), a década de 1990 - governos Collor, Franco e Cardoso- foi caracterizada pela obediência aos enunciados do Consenso de Washington, do Fundo Monetário Internacional (FMI) e do Banco Mundial (BM), que propugnavam um ajuste estrutural, consistente na negociação da dívida externa, estabilização dos preços, necessidade de geração de superávits primários, tudo isso com muitos custos sociais (REIS, et Al, 2007, p. 356) 6 .

${ }^{7}$ Esta mudança na conformação do espaço e das relações entre classes foi a multireferida "modernização conservadora". Não se trata de um fenômeno exclusivo do Brasil, mas dos países subdesenvolvidos em geral, com alguma ou outra peculiaridade aqui e ali, mas com muitas similaridades (SANTOS, 1993, p. 105). 
${ }^{8}$ Conforme Silva (2008, p. 29), “a política de modernização agrícola dos governos militares (...) contribuiu para o aumento da concentração fundiária que teve como resultado outro grande êxodo rural, novamente em direção aos centros urbanos".

9 A urbanização crescente nada mais representou senão uma fatalidade para um país subdesenvolvido no qual ela ocorreu com o "aumento do desemprego, do subemprego e do emprego mal pago e a presença de volantes nas cidades médias e nas cidades pequenas" (SANTOS, 1993, p. 121).

${ }^{10}$ Jaqueline Mallmann Haas e Clayton Hilling Hillig apontam que a mudança na dicotomia rural/urbano significou a reinvenção do rural, que passa a ser marcado pela positividade, afastando-se da identificação com atraso e pobreza $(2009 \text {, p. } 3)^{10}$.

${ }^{11}$ Em entrevista concedida à Revista Fractal, consta maior reflexão sobre o tema. Nesta oportunidade, Wacquant comenta sobre as ilusões 're" (reintegração, reeducação, reinserção), dizendo que os presos não são integrados, portanto, não poderiam ser reintegrados (WACQUANT, 2008)

${ }^{12} \mathrm{Na}$ verdade, ele diz que o Estado de Bem-Estar Social nos Estados Unidos é melhor nominado pela terminologia Estado caritativo, já que neste país o Estado-providência na verdade é uma versão capenga dos seus similares europeus, pois, em razão de questões históricas, "o princípio que guia a ação pública americana na matéria não é a solidariedade, mas a compaixão; seu objetivo não é fortalecer os laços sociais (e ainda menos reduzir as desigualdades), mas no máximo aliviar a miséria mais gritante" (WACQUANT, 2003, p. 20)

${ }^{13}$ Vale salientar um trecho da exposição do autor: “(...) O termo 'avançada' pretende indicar que aquelas formas de marginalidade não estão em nosso passado, nem sendo absorvidas progressivamente, seja pela expansão do 'livre mercado' (isto é, por meio de um aprofundamento da mercantilização da vida social'), seja através dos braços do Estado de Bemestar social, porém, mais exatamente, impõem-se em nosso futuro. A menos que novas formas de intervenção política sejam elaboradas para coibir ou redirecionar as forças estruturais que as produzem - entre outras, o crescimento econômico concentrado e a dualização do mercado de trabalho; a casualidade do emprego e a autonomização da economia de rua em áreas urbanas degradadas; o desemprego em massa que conduz a uma completa desproletarização para grandes segmentos da classe trabalhadora, especialmente entre os jovens; e políticas estatais de contenção de gastos urbanos, quando não de total abandono - e que novos mecanismos de medição social sejam postos em prática para reincorporar as populações excluídas, espera-se que a marginalidade urbana continue a aumentar e a difundir-se, e, com ela, a violência de rua, a alienação política, a desertificação organizacional e a informalização da economia que infestam cada vez mais os bairros de excluídos das metrópoles na sociedade avançada" (WACQUANT, 2001, p. 165-166)

${ }^{14}$ Explica Wacquant que "(...) em vez de difundir-se por todas as áreas da classe trabalhadora, a marginalidade avançada tende a concentrar-se em territórios bem-identificados, bemdemarcados e cada vez mais isolados, vistos por pessoas de dentro e de fora como purgatórios sociais, infernos urbanos onde apenas o refugo da sociedade aceita habitar. Um estigma referente ao lugar sobrepõe-se assim ao já universal estigma da pobreza e (onde aplicável) da raça ou da origem colonial-imigrante" (2001, p. 168). Aliada à fixação e estigmatização territoriais, ele ainda acrescenta o fator de alienação territorial, ou seja, "a dissolução do 'lugar', isto é, a perda de um local com o qual as populações marginalizadas identifiquem-se e no qual sintam-se seguras"; assim, as áreas degradadas tornam-se nada mais que "espaços indiferentes de mera sobrevivência e de luta" (Ibidem, p. 169) 
15 Para exemplificar, citamos as discussões em torno da promulgação do Código Penal dos Estados Unidos do Brazil (1890-1940) e do Código Penal de 1940, que refletem as concepções difundidas na época sobre o fenômeno do crime. Quando da promulgação do Código Penal dos Estados Unidos do Brazil, já era corrente nos meios acadêmicos a necessidade de um novo Código Penal, mais afinado com os novos paradigmas da justiça criminal na Europa e nos Estados Unidos. O Código de 1890 trazia valores liberais (firmados na ideia da igualdade humana - Escola Clássica do Direito Penal), porém, tais preceitos esbarravam na extrema desigualdade social e racial. As elites pretendiam a sua reforma justamente para incluir dispositivos capazes de controlar determinados segmentos da população (ALVAREZ, SALLA e SOUZA, 2003). A elite intelectual brasileira acolhia com grande interesse as então difundidas concepções da criminologia positivista de Lombroso, Ferri e Garofalo, conforme explanado por Souza, resultando em um choque entre as Escolas Penais. Estabeleceu-se uma tendência de enxergar o Direito Penal como voltado à defesa social, em proposta ampliadas pelos discursos médicos da Medicina Legal, da eugenia e do higienismo. Alvarez, Salla e Souza (2003) explicam que, embora não houvesse um êxito inicial da corrente teórica positivista, que buscavam a modificação do Código Penal de 1890, por outro lado elas triunfaram, pois durante a sua vigência desenvolveram-se políticas públicas voltadas para a segurança, como a polícia, as prisões e os manicômios. O Código Penal de 1940, que o sucedeu, sofreu bastante influência da Escola Positiva italiana, o que já se podia antever, ante a Luta das Escolas decorrente da crítica ao Código Penal de 1890.

${ }^{16}$ Rosa Del Olmo, em seu livro "A América Latina e sua Criminologia" (2004), coloca em relevo a existência de um 'imperialismo científico', mascarado sob a capa ideológica do 'intercâmbio internacional' em matéria de prevenção do delito e de tratamento do delinquente (DEL OLMO, 2004, p. 78). Ela demonstra como as classes dominantes na América Latina absorviam e aplicavam o que lhes era interessante das doutrinas estadunidenses e europeias, com maior impacto das primeiras, assumindo a ideologia liberal e o positivismo como formas de legitimar a dominação de classe (Ibidem, 2004, p. 164).

${ }^{16}$ A imagem do criminoso geralmente corresponde a uma pessoa membro das classes mais baixas da população; no entanto, não se pode deixar de perceber que muitas das violações praticadas em face da sociedade são praticadas pelos mais ricos, como crimes tributários e econômicos (crimes de colarinho branco.

${ }^{17}$ A imagem do criminoso geralmente corresponde a uma pessoa membro das classes mais baixas da população; no entanto, não se pode deixar de perceber que muitas das violações praticadas em face da sociedade são praticadas pelos mais ricos, como crimes tributários e econômicos (crimes de colarinho branco.

${ }^{18}$ Neste ponto, deve-se ressaltar que, além da apropriação do espaço pelo agronegócio, ainda existem muitas terras destinadas à especulação, ou seja, improdutivas. De todo modo, estas terras improdutivas e destinadas à especulação imobiliária também estão nas mãos dos interesses do capital. 